\title{
Density structure and isostasy of the lithosphere in Egypt and their relation to seismicity
}

\author{
Mikhail K. Kaban ${ }^{1,2}$, Sami El Khrepy ${ }^{3,4}$, and Nassir Al-Arifi ${ }^{3}$ \\ ${ }^{1}$ GFZ German Research Centre for Geosciences, Telegrafenberg A 20, 14473 Potsdam, Germany \\ ${ }^{2}$ Schmidt Institute of Physics of the Earth, Moscow, Russia \\ ${ }^{3}$ King Saud University, P.O. Box 2455, Riyadh 11451, Saudi Arabia \\ ${ }^{4}$ National Research Institute of Astronomy and Geophysics, NRIAG, 11421, Helwan, Egypt
}

Correspondence: Mikhail K. Kaban (kaban@gfz-potsdam.de) and Sami El Khrepy (selkhrepy@ksu.edu.sa)

Received: 26 January 2018 - Discussion started: 6 March 2018

Revised: 14 June 2018 - Accepted: 18 June 2018 - Published: 6 July 2018

\begin{abstract}
A joint analysis of the new satellite-terrestrial gravity field model with recent data on the crustal structure and seismic tomography was conducted to create an integrative model of the crust and upper mantle and to investigate the relation of the density structure and the isostatic state of the lithosphere to the seismicity of Egypt. We identified the distinct fragmentation of the lithosphere of Egypt in several blocks. This division is closely related to the seismicity patterns in this region. The relatively dense and strong lithosphere in the Nile Delta limits the seismic activity within this area, while earthquakes are mainly associated with the boundaries of this block. In the same way, the relatively strong lithosphere in the Isthmus of Suez and northern Mediterranean prevents the Gulf of Suez from opening further. The central part of Egypt is generally characterized by an increased density of the mantle, which extends to the Mediterranean at a depth of $100 \mathrm{~km}$. This anomaly deepens southward to Gilf Kebir and eastward to the Eastern Desert. The average density of the crystalline crust is generally reduced in this zone, indicating the increased thickness of the upper crust. The low-density anomaly under the northern Red Sea is limited to $100-125 \mathrm{~km}$, confirming the passive origin of the extension. Most of the earthquakes occur in the crust and uppermost mantle in this structure due to the hot and weak upper mantle underneath. Furthermore, an asymmetric lithosphere structure is observed across the northern Red Sea. The isostatic anomalies show the fragmentation of the crust of Sinai with the high-density central block. Strong variations in the isostatic anomalies are correlated with the high level of seismicity around Sinai. This tendency is also evi-
\end{abstract}

dent in the northern Red Sea, east of the Nile Valley, and in parts of the Western Desert.

\section{Introduction}

A thorough understanding of the solid Earth system is an essential step towards deciphering the link between the dynamic processes in the Earth system and near-surface processes. In particular, the density heterogeneity of the lithosphere and upper mantle largely controls tectonic processes, which in turn produce strong density perturbations in the upper crust. Therefore, knowledge of density variations is essential to understand the structure and dynamics of the lithosphere. Up to now, seismological methods have been a key to unraveling the structure of the crust and upper mantle and provide an increasingly detailed image of the interior of the Earth. However, they cannot provide a complete image of the structure of the crust and upper mantle. For example, seismic velocities in the upper mantle are more sensitive to temperature than to compositional variations (e.g., Tesauro et al., 2014); therefore, tomography images primarily reflect temperature variations. A clear example is represented by high-density eclogitic rocks, which are characterized by seismic velocities that are close to normal upper mantle conditions and therefore are almost invisible in seismic models (Krystopowicz and Currie, 2013). It is also important that different seismological methods provide different estimates of various parameters. On the other hand, the gravity field of the Earth, which directly images density variations, cannot 
be used separately to model density heterogeneity. The inverse gravity problem is essentially ill-posed and its solution depends completely on initial model assumptions. Therefore, the identification of density variations in the crust and upper mantle is challenging and this problem cannot be solved by a particular geophysical method alone. Recent efforts have aimed at integrating multiple geophysical and petrological datasets into a common interpretation framework (e.g., Fullea et al., 2009; Gradmann et al., 2013; Kaban and Mooney, 2001; Kaban et al., 2014a).

Many seismic studies (chiefly reflection and refraction profiles and receiver function observations) have been performed in Egypt; however, most of them are related to the northern and eastern parts of the country along the Red Sea and Mediterranean. With respect to recent results, we refer to Abdelwahed et al. (2013), showing the Conrad and Moho discontinuities of eastern Egypt and the Red Sea. Corchete et al. (2017) determined the crustal and uppermost mantle structure in northeastern Egypt based on Rayleigh wave analysis. Hosny and Nyblade (2016) determined the vertical $V_{\mathrm{s}}$ profiles of the crust and the Moho depth for 26 stations in Egypt; however, only a few of them are located in the central and southeastern parts. Most of the previous seismic determinations of the crustal structure were summarized in Stolk et al. (2013) in the crustal model of Asia, which also includes northeastern Africa. These studies show that the coverage of the territory of Egypt based on seismic methods is very heterogeneous. While the areas adjoining the Red Sea and Mediterranean are well studied (El Khrepy et al., 2015, 2016a, b; Hosny and Nyblade, 2016; Mohamed et al., 2014), the data for the central, western, and southern parts are sparse. Several important questions remain unresolved. The main question relates to the structural division of the lithosphere and to what extent the surface tectonic units are related to the deep heterogeneity of the crust and upper mantle.

Recent satellite gravity missions (mainly GRACE and GOCE) provided the possibility to produce new-generation gravity models based on the combination of satellite and terrestrial data including land areas (complementary to satellite radar altimetry; e.g., Förste et al., 2014). These models stimulated new studies of the crustal structure, particularly the determination of the Moho boundary in Egypt and surrounding areas (e.g., Azab et al., 2015; Cowie and Kusznir, 2012; Prutkin and Saleh, 2009; Salem et al., 2013; Sobh et al., 2016). The results obtained in these studies are very controversial. As already mentioned, the solution to the ill-posed inverse gravity problem highly depends on initial assumptions. The Earth's gravity field is induced by the density heterogeneity of the entire planet; therefore, its inversion with respect to one to two parameters (e.g., for the determination of the Moho depth and density contrast at this boundary) often provides biased results. Only an interpretation integrating all available geophysical, geological, and mineral physics data might help to overcome this internal weakness of the gravity approach (inversion). Kaban et al. (2016c) presented an integrative model based on a joint analysis of seismic and gravity data for the whole Middle East, which partially covers the area of the present study. However, for the territory of Egypt this model is not defined in that study due to the lack of data, in particular on the crustal structure. Another problem is related to the evaluation of the isostatic state of the lithosphere, which is often related to seismicity (e.g., Assumpção and Sacek, 2013; Sobiesiak et al., 2007). Segev et al. (2006) published a comprehensive study on this topic for the Levant continental margin and the southeastern Mediterranean area; however, this study covers only a small part of Egypt.

One of the motivating objectives is to find an interpretation for the very low seismicity pattern in northern Egypt (e.g., in the Nile Delta; Fig. 1), which is bounded by seismically active regions (ENSN earthquake catalogues, 19972016), in relation to lithosphere structure in this region that includes highly populated areas and intensive international trade ways. On the other hand, the high level of seismicity and the shallow depth of hypocenters in the northern Red Sea should be also investigated with respect to the structure of the crust and upper mantle and to the isostatic state of the lithosphere. The asymmetric seismicity pattern in the northern Red Sea is another subject for discussions. Furthermore, the termination of the Gulf of Suez rift without continuation to the Mediterranean Sea will be also analyzed in relation to the density structure of the lithosphere.

In the present study, we use an integrative interpretation of gravity, seismic, geological, and mineral physics data for the investigation of the density structure of the crust and upper mantle in Egypt and its surroundings to evaluate the isostatic state of the lithosphere and its relation to the seismicity in this region. Such an integrative geophysical study is applied to the study area for the first time; this was made possible due to the availability of new data after establishing in 1997 the Egyptian National Seismic Network (ENSN), which provided the input for new receiver functions and tomography models of the Egyptian lithosphere (e.g., El Khrepy et al., 2015, 2016; Abdelwahed et al., 2013; Hosny and Nyblade 2016; Mohamed et al., 2014).

\section{Tectonic settings and seismicity of Egypt}

The lithosphere of Egypt formed in a very active tectonic frame. In the north, it is bounded by the continental collision zone in which the African Plate subducts under Eurasia with a velocity of approximately $6 \mathrm{~mm} \mathrm{yr}^{-1}$ (McClusky et al., 2000). The left-lateral strike-slip Dead Sea Transform continues to the Aqaba fault zone at the northeastern boundary. On the eastern side, the Red Sea represents an active extension zone dividing the African and Arabian plates at a variable extension rate, which increases from the north $\left(\sim 5.6 \mathrm{~mm} \mathrm{yr}^{-1}\right)$ to the south $\left(14 \mathrm{~mm} \mathrm{yr}^{-1}\right.$; McClusky et al., 2003). This active environment produces high and continuous seismic activity in the region (Fig. 1). Sinai represents a 


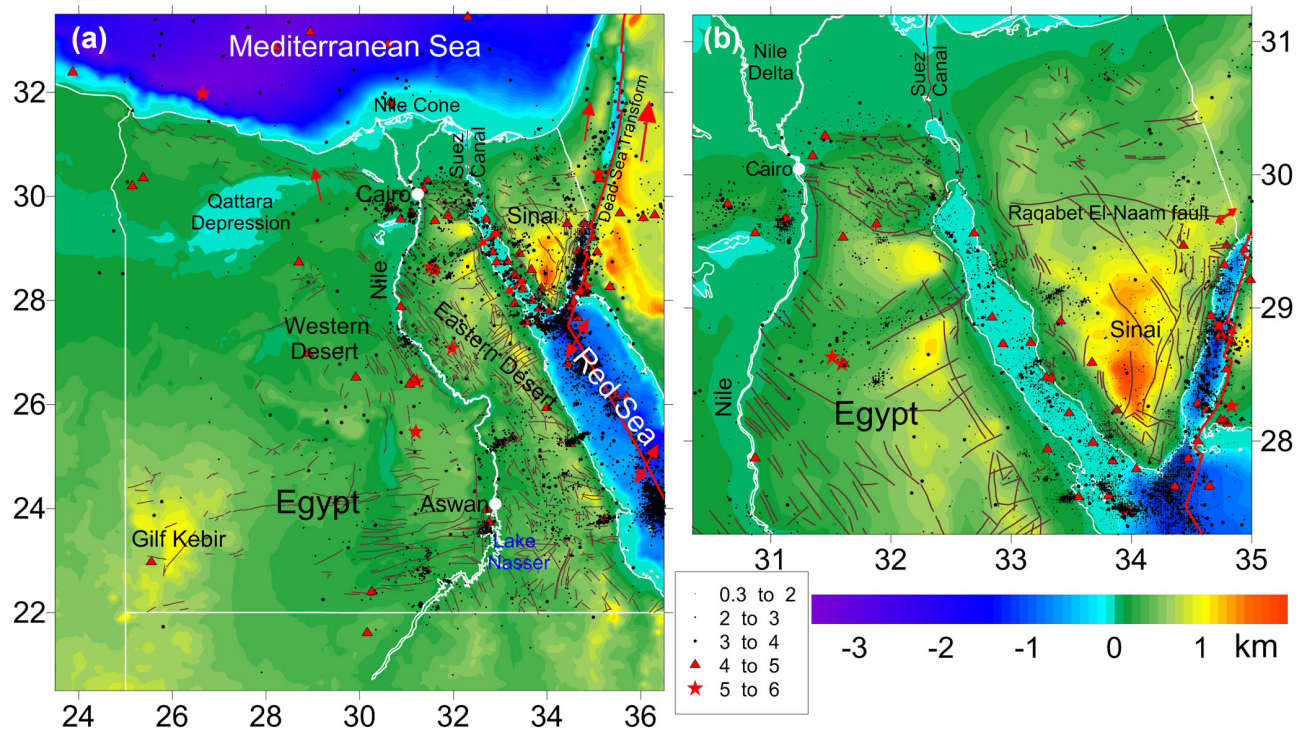

Figure 1. Topography of Egypt and surrounding area. A zoomed image of the northeastern part of the study area, which is seismically most active, is shown in the right. Black dots, red triangles, and stars show the seismicity of Egypt (Egyptian National Seismological Catalogue, ENSN, 1998-2011). In the map of the whole region, only earthquakes with magnitudes $>2$ are demonstrated. Brown lines show faults (Egyptian Geologic Survey and Mining Authority, EGSMA, 1992). Red arrows demonstrate principal trends of the plate motions (Stern and Johnson, 2010). The red line delineates the boundary between the African and Arabian plates. The axes show the geographical coordinates in degrees.

sub-block of the lithosphere (microplate), which is bounded by the Aqaba and Suez fault zones. It is still under debate as to which principal continental plate, the African or Eurasian, it can be attributed with respect to its deep structure and dynamics. West of the Red Sea, the Eastern Desert extends to the Nile Valley. In the south, it is a part of the Nubian Shield, while the northern and northeastern parts are covered by Eocene sediments. The Western Desert covers the majority of Egypt west of the Nile Valley. The Gilf Kebir Plateau is located in the southwestern corner of Egypt (Fig. 1).

Due to its location in the northeastern African continent, seismic activity in Egypt is mainly controlled by regional stresses from active tectonic surroundings. The interaction of tectonic processes results in different levels of seismicity in Egypt, mostly limited to the crust and upper mantle (Fig. 1). Clustered and scattered earthquake activity are well defined to the parallel shear zones along the western coast of the Red Sea, the entrance and axial trough of the Gulf of Suez, the Cairo Suez region, and the eastern part of Egypt. The most intensive zones of earthquake activity and earthquake swarms are located in the northern Red Sea, the southern Sinai tip, and the two gulfs of Aqaba and Suez, especially at the intersection of the plate boundaries, while the western part of Egypt is seismically stable, with no remarkable activity (El Khrepy et al., 2015, 2016a, b). The seismicity pattern is directed NW-SE in the Red Sea and Gulf of Suez, in accordance with the Red Sea rift direction. The earthquakes in the Gulf of Aqaba tend NE in the direction of the Dead Sea rift. The seismicity of the northern coast of Egypt is related to eastern Mediterranean tectonics associated with the surrounding plate boundaries (Cyprian and Hellenic arcs, Anatolian Fault System; Fig. 1). The seismicity along the Nile River occurs in scattered cluster patterns; the seismic zones along the Nile Valley correspond to its structural configuration (Fig. 1). In southern Egypt, two types of earthquakes occur in the Aswan area: natural earthquakes due to the activity of the Kalabsha fault in the southwest of Aswan and induced earthquake activity corresponding to the artificial Lake Nasser.

Therefore, the seismic activity in Egypt and its surroundings is controlled by many factors. One of our objectives is to determine the relationship between earthquake activity and the density structure of the crust and upper mantle, which are directly related to active geodynamics in this region.

\section{Method and initial data}

\subsection{General modeling approach}

In this section we describe a general approach for the integrative analysis of gravity and other geophysical data that was developed and applied previously for Europe, North America, and some parts of Asia (Kaban et al., 2010, 2014a, 2015, 2016a). All details on the methods and datasets used will be provided in the following sections. This approach includes the following steps. 
1. Construction of the initial model of the crust based on available seismic and geological data. This procedure for irregularly distributed data is extensively discussed in Stolk et al. (2013). The crustal model includes at least two layers, sediments and crystalline crust, which are characterized by horizontal and vertical variations in seismic velocities and density. The densities of the sediments and crystalline crust are determined in a different way. For sediments, we define several types of basins, from "soft" to "hard", which are characterized by different density-depth relations. These relations are determined based on borehole, compaction, and seismic data (Stolk et al., 2013). The density of the crystalline crust is determined from empirical relationships with seismic velocities (Christensen and Mooney, 1995).

2. The gravity effect of the crust is computed and removed from the observed gravity field. In addition, we remove the effect of deep mantle (below $325 \mathrm{~km}$ ) heterogeneity based on existing global dynamic models (Kaban et al., 2014b, 2015). The residual gravity anomalies mainly represent the effect of the uppermost mantle and density anomalies of the crust not included in the initial model, with other uncertainties of the crustal parameters. In the same way, we calculate the residual topography that represents the part of the observed topography-bathymetry that is not compensated for by crustal density variations including the Moho boundary. Both these parameters depend on upper mantle density variations but in essentially different ways, which provides the possibility to resolve the vertical density structure (Kaban et al., 2015).

3. To study the upper crust and evaluate the isostatic state of the lithosphere, high-resolution local isostatic anomalies are computed (Kaban et al., 2016b).

4. The initial 3-D density model of the upper mantle is created based on available seismic models. The velocity-todensity conversion factor is computed based on mineral physics relations (e.g., Tesauro et al., 2014).

5. The residual mantle gravity anomalies and residual topography are jointly inverted to estimate the 3-D density variations in the upper mantle. The inversion is constrained by the initial model (step 4); the corrections should be minimal. This way, a stable and unique solution can be found. The joint inversion of the residual gravity and residual topography provides the possibility to resolve the vertical density stratification much better than the inversion of the residual gravity anomalies alone because the residual gravity and topography depend on the density heterogeneity, but in fundamentally different ways depending on the size and depth of the density anomalies. A clear example is a vertical dipole density structure, which is characterized by near-zero

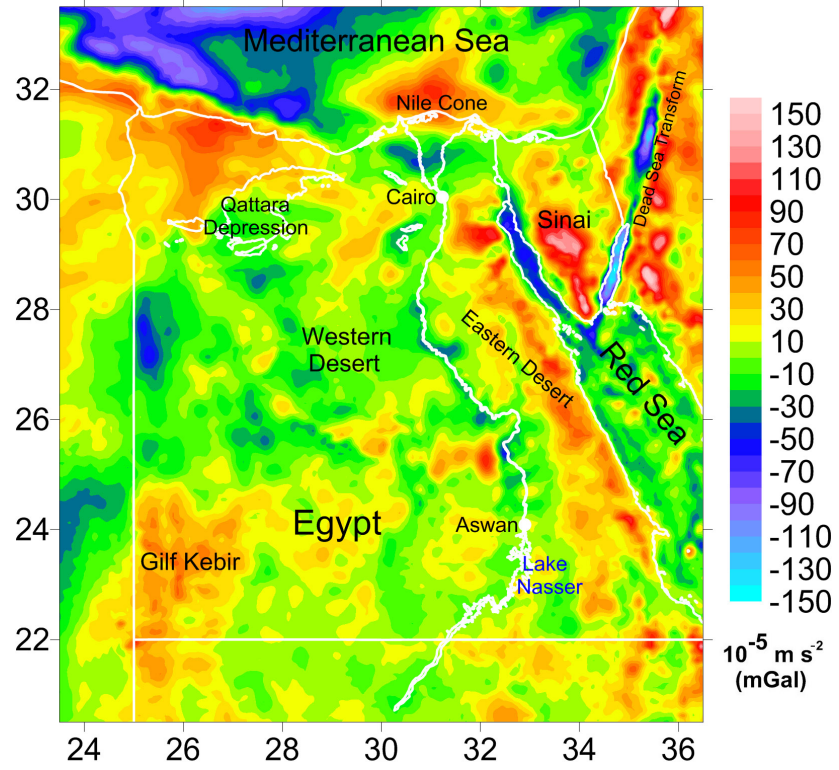

Figure 2. Free-air gravity disturbances from the combined satelliteterrestrial gravity model EIGEN-6c4 (Förste et al., 2014). The maximum resolution $(\sim 10 \times 10 \mathrm{~km})$ corresponds to degree / order 2190.

residual topography; however, the gravity field anomaly is very distinctive (Kaban et al., 2015). The uncertainties related to the initial crustal model might be significant, especially in the areas without seismic constraints; therefore, in making the inversion we allow for additional corrections of the crustal densities and Moho variations.

\subsection{Initial gravity field}

The initial gravity field (free-air gravity disturbances) is based on the combined satellite-terrestrial model EIGEN6c4 (Förste et al., 2014; Fig. 2). The maximal resolution corresponds to 2190 spherical harmonic degree / order $(\sim 10 \mathrm{~km}$ spatially); however, the actual one depends on the terrestrial observations included in the model. The long-wavelength part, which is constrained by satellite data (chiefly GRACE and GOCE), is limited to degree / order 240. This resolution is sufficient for modeling of the upper mantle structure since the maximal resolution of the initial data does not exceed $1^{\circ} \times 1^{\circ}$. However, for the computation of the local isostatic anomalies the full gravity field is employed.

\subsection{Model of the crust}

We use the EPcrust model (Molinari and Morelli, 2011) as a basis for the western part of the study area and the crustal model of Kaban et al. (2016) for the eastern part. These models have been improved by using several regional datasets. The detailed map of Rybakov and Segev (2004) has been em- 


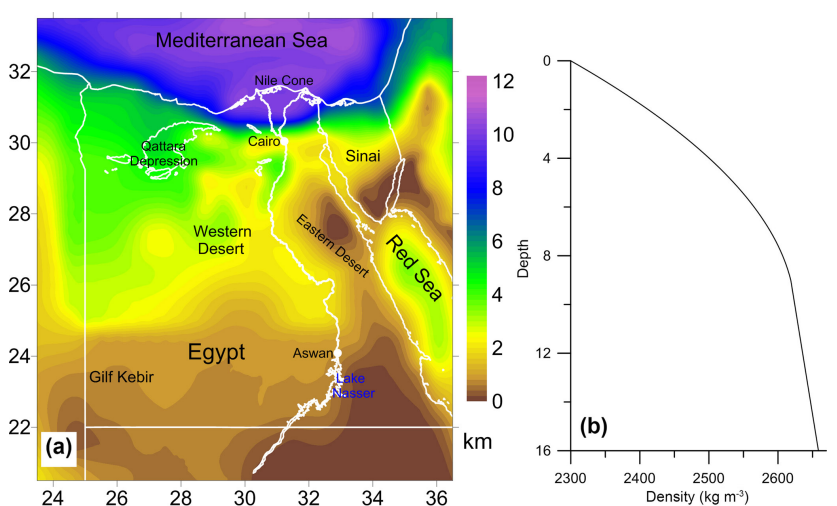

Figure 3. (a) Thickness of sediments for Egypt with surroundings. Gray lines show faults. (b) Density-depth relationship used for the calculation of the gravity effect of sediments.

ployed for the position of the basement in the northern part of the study area. The resulting thickness of sediments is shown in Fig. 3a. The density of sediments was estimated according to the average density-depth relationship (Fig. 3b), which is based on a compilation of various datasets taking into account the density compaction by Stolk et al. (2013) and then adjusted for the regional data by Kaban et al. (2016). This relationship reflects only a regional trend; therefore small-scale residual anomalies still reflect the local density heterogeneity of the sedimentary layer.

The Moho model is verified by using original seismic determinations. Most of them are taken from the database of the US Geological Survey (Mooney, 2010, with updates until April 2017). In addition, the recent receiver function determinations of Hosny and Nyblade (2016) are included (Fig. 4a). For interpolation we used a remove-compute-restore technique developed earlier by Stolk et al. (2013). At the first stage, the measured Moho depths were corrected for the Airy type of isostasy by employing the surface load, which includes the topography-bathymetry and density heterogeneity of sediments. Here, the type of isostatic compensation is not of primary importance since this correction is restored at the last stage. As demonstrated by Stolk et al. (2013), the residual Moho values show much fewer variations than the original ones and can be easily interpolated. After interpolation with the ordinary kriging technique, the isostatic correction was restored. Therefore, the resulting Moho map fully fits to the original determinations, but demonstrates much better correspondence to the tectonic features than it would for a direct interpolation. In this way, for example, it is possible to trace extended topography features like the Red Sea in the study are, which are measured only in limited places. This map was then merged at the boundaries with the abovementioned basic models (Fig. 4a). It should be clarified that the Moho depths are defined only in the vicinity of the primary data points (Fig. 4a); in other areas the model represents an
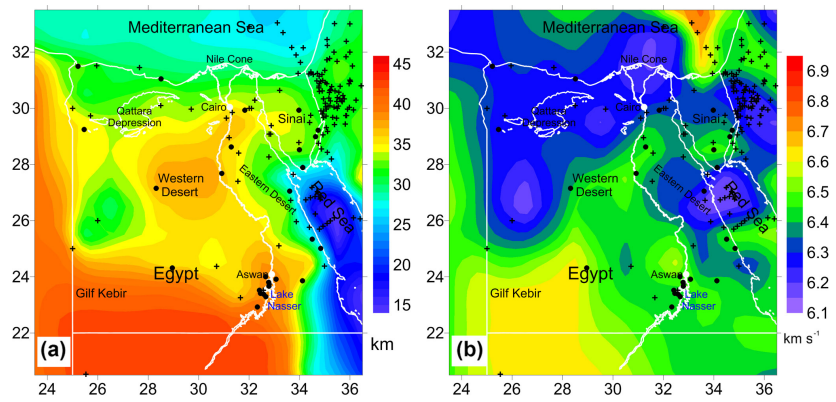

Figure 4. (a) Depth to the Moho. Crosses show determinations of the crustal structure from the database of the US Geological Survey (Mooney, 2010, with updates up to April, 2017) and circles represent the receiver function results of Hosny and Nyblade (2016). (b) Average P-wave velocities in the crystalline crust. Crosses show determinations from the database of the US Geological Survey (Mooney, 2010, with updates up to April, 2016) and circles represent the receiver function results of Hosny and Nyblade (2016). The last ones have been converted from $\mathrm{S}$-wave velocities.

initial approximation, which should be improved in further inversion.

For the crystalline crust, the average P-wave seismic velocities $(\mathrm{Vp})$ were determined. For this, the $\mathrm{S}$-wave vertical profiles of Hosny and Nyblade (2016) were converted to Vp using the $\mathrm{Vp} / \mathrm{Vs}$ ratios provided. The limited amounts of seismic determinations do not provide the possibility to construct a multilayer model; however, for the gravity calculations, average values are sufficient to estimate the cumulative effect of the crystalline crust (Kaban et al, 2016a). The interpolated data were merged with basic regional models (Fig. 4b).

The variations in $\mathrm{Vp}$ show the fragmentation of the crystalline crust in Egypt and surrounding areas. The central and northern parts of Egypt and the Sinai massif are characterized by nearly normal velocities $\left(6.4-6.6 \mathrm{~km} \mathrm{~s}^{-1}\right)$, which are typical for the continental crust (Christensen and Mooney, 1995). The velocities in the northern and northwestern parts significantly decreased to $6.1-6.3 \mathrm{~km} \mathrm{~s}^{-1}$; the same is true for parts of the Western Desert and the northern Red Sea. We also observe a W-E trend from low to high velocities in the Mediterranean, which likely corresponds to the transition from oceanic to continental crust (Fig. 4). The maximum around Gilf Kebir is not well defined because it is based on two marginal determinations only. The velocities of the crystalline crust were converted into densities by employing the nonlinear relationships of Christensen and Mooney (1995).

\subsection{Initial density model of the upper mantle}

The initial density model of the upper mantle is based on the tomography model of Schaeffer and Lebedev (2013), which is converted to density variations by applying the mineral physics method of Stixrude and Lithgow-Bertelloni (2005). 

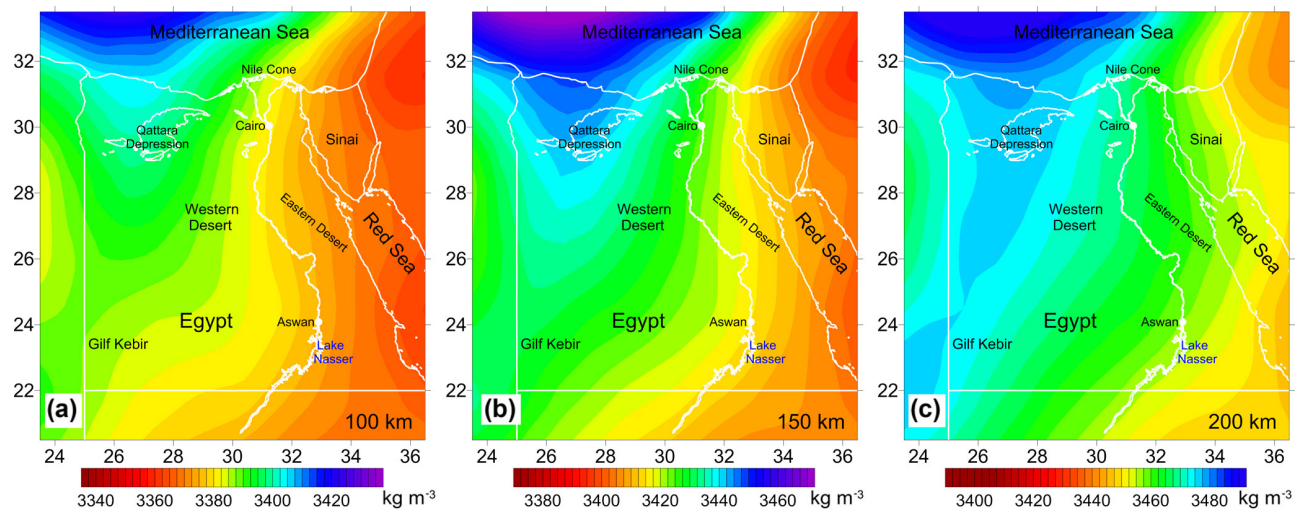

Figure 5. Initial density model of the upper mantle based on the tomography model of Schaeffer and Lebedev (2013) for depths of (a) $100 \mathrm{~km}$, (b) $150 \mathrm{~km}$, and (c) $200 \mathrm{~km}$.

Table 1. Reference density of the crustal and upper mantle layers.

\begin{tabular}{lrrrr}
\hline & $\begin{array}{r}\text { Upper } \\
\text { crust }\end{array}$ & $\begin{array}{r}\text { Lower } \\
\text { crust }\end{array}$ & $\begin{array}{c}\text { Uppermost } \\
\text { mantle }\end{array}$ \\
\hline Depth $\left(\mathrm{km}^{2}\right.$ & $0-15$ & $15-40$ & 50 & 100 \\
Density $\left(\mathrm{kg} \mathrm{m}^{-3}\right)$ & 2700 & 2940 & 3357 & 3384 \\
\hline & \multicolumn{4}{c}{ Upper mantle } \\
\hline Depth $\left(\mathrm{km}^{-3}\right.$ & 150 & 200 & 250 & 300 \\
Density $\left(\mathrm{kg} \mathrm{m}^{-3}\right)$ & 3419 & 3457 & 3510 & 3560 \\
\hline
\end{tabular}

A complete description of this technique can be found in Tesauro et al. (2014) and Kaban et al. (2016a). Three slices of density variations for the depths 100,150 , and $200 \mathrm{~km}$ are shown in Fig. 5. The model demonstrates general trends in the area; the density mainly decreases towards the Red Sea at a depth of $100 \mathrm{~km}$ in the W-E direction (Fig. 5a). At a greater depth, a strong positive anomaly associated with the subducting African lithosphere extends to the south (Fig. 5b, c).

\section{Results}

\subsection{Residual mantle gravity anomalies and residual topography}

The gravity effect of the crust was determined based on the constructed crustal model. All calculations are performed relative to a reference density model (Table 1). The density of the crustal layers corresponds to the estimates of Christensen and Mooney (1995). The mantle densities are determined as the global averages estimated based on the seismic velocities provided by the model of Schaeffer and Lebedev (2013), assuming a "fertile" composition of the upper mantle material (Tesauro et al., 2014). The parameters of this model are the same as those used in studies of other regions and on larger
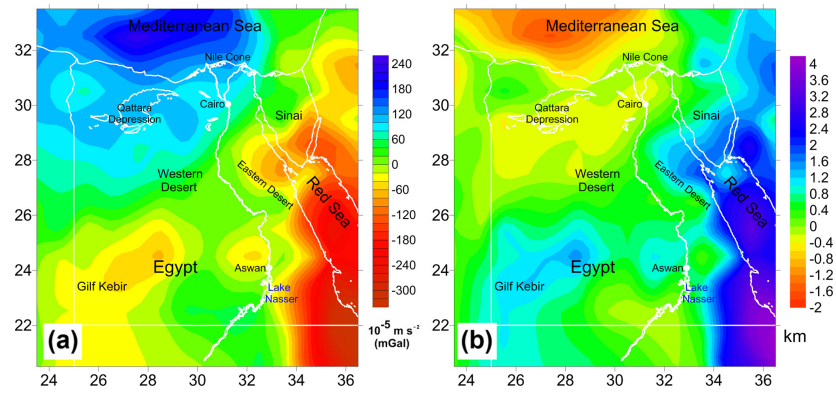

Figure 6. Residual mantle gravity anomalies (a) and residual topography (b) calculated by removing of the crustal and deep mantle fields from the observed gravity.

scales (e.g., Kaban et al., 2016), which provides the possibility for direct comparison of the results. It should be noted that the parameters of the reference model are not critical for the results since they mainly affect the average level of both the residual gravity field and residual topography, while we interpret only lateral variations in these fields (Mooney and Kaban, 2010).

Because the effect of deep layers strongly depends on remote areas and might represent significant trends (even between the Northern and Southern Hemisphere), the highresolution model of Egypt including the surrounding areas has been embedded in the global model. For this purpose, we used CRUST1.0, which was improved for North America and Eurasia based on recent models for these continents (Mooney and Kaban, 2010; Stolk et al., 2013). The details of the computational technique are described in Kaban et al. (2016b). The residual anomalies obtained by removing the crustal effect from the observed gravity field are shown in Fig. 6a. The resolution of this field is limited to $1^{\circ} \times 1^{\circ}$ (grid cell size), since the resolution of the crustal model does not provide more details, even in the places with dense seismic observations (Fig. 4). As already mentioned, we also removed the effect of the deep mantle heterogeneity below 
$325 \mathrm{~km}$ based on a global dynamic model described in Kaban et al. (2015, 2016a). This depth is chosen based on our previous studies as the depth, which exceeds the maximal depth of the lithospheric roots. This is important since the inversion is performed globally (Kaban et al., 2015). These calculations are based on the global tomography model s40rts of Ritsema et al. (2011). For the upper mantle it corresponds well to the model of Schaeffer and Lebedev (2013), but its resolution is lower. While calculating the dynamic topography, we take into account the dynamic effects of the mantle convection (Kaban et al., 2015).

In addition to the residual gravity anomalies, the residual topography was also computed based on the same crustal model (Fig. 6b). The residual topography acts as load, which is not compensated for by crustal density variations including the Moho.

$t_{\mathrm{res}}=\frac{1}{\bar{\rho}}\left(\rho_{\mathrm{top}}\right) t_{\mathrm{obs}}+\frac{1}{\bar{\rho}} \int_{0}^{M} \Delta \rho(h) \mathrm{d} h$,

where $\rho_{\text {top }}\left(\mathrm{kg} \mathrm{m}^{-3}\right)$ is the average density above sea level (including sediments and ice); $t_{\mathrm{obs}}(\mathrm{km})$ is the topography (zero offshore); $\bar{\rho}=2670 \mathrm{~kg} \mathrm{~m}^{-3}$ is the standard density of topography; $\Delta \rho(h)=\rho-\rho_{\text {ref }}\left(\mathrm{kg} \mathrm{m}^{-3}\right)$ is the relative density below sea level including the negative relative density of water in the oceanic domain; $h(\mathrm{~km})$ is the depth from sea level; and $M(\mathrm{~km})$ is the depth to the Moho (below the Moho density variations are assumed to be $\Delta \rho(h)=0$ at this stage). The dynamic effect of the mantle below $325 \mathrm{~km}$ was removed from the residual topography in the same way as for the residual gravity. Therefore, the residual topography reflects the effect of the upper mantle density variations, which are not taken into account.

Potential uncertainties of the residual field were analyzed in detail in Mooney and Kaban (2010) and Kaban et al. (2016a). They conclude that for relatively extended anomalies, which are based on several crustal determinations, the uncertainty of the residual gravity should not exceed $\sim 40 \times 10^{-5} \mathrm{~m} \mathrm{~s}^{-2}$ (mGal), which is much less than the total anomaly $\left(-300\right.$ to $\left.250 \times 10^{-5} \mathrm{~m} \mathrm{~s}^{-2}\right)$. Szwillus and Ebbing (2016) provide even smaller values for uncorrelated uncertainties of the crustal model. The corresponding error of the residual topography is $\sim 0.35 \mathrm{~km}$. However, this conclusion only corresponds to the areas with seismic determinations of the crustal structure (Fig. 4). In the following inversion of the residual fields together with seismic tomography we consider a possibility for further corrections of the initial density model.

The residual fields significantly differ from the previous study of the whole Middle East (Kaban et al., 2016c). This is mainly due to new data on the crustal structure, which are included in the present model. One can observe a clear division of the area into several distinctive patterns. The northwestern part is characterized by positive residual gravity anomalies, while negative anomalies dominate in the Red
Sea, with some extension to the continental part including Sinai (Fig. 6a). The residual topography generally mirrors the residual gravity; however, the amplitudes of the anomalies are not related straightforwardly, since the effects of any density anomaly on the surface gravity field and topography differently depend on its depth and size (Fig. 6b). These fields will be used to adjust the density models of the crust and upper mantle in the following sections.

\subsection{Density model of the upper mantle}

The 3-D density model of the mantle has been constructed through joint inversion of the mantle gravity anomalies (Fig. 6a) and residual topography (Fig. 6b) constrained by the initial density model based on seismic tomography (Fig. 5). The inverse problem implies the minimization of the functional

$\min \left\{\left\|A \rho-g_{\text {res }}\right\|^{2}+k\left\|B \rho-t_{\text {res }}\right\|^{2}+\alpha\left\|\rho-\rho_{\text {ini }}\right\|^{2}\right\}$,

where $A$ and $B$ are the integral operators converting the densities $\rho\left(\mathrm{kg} \mathrm{m}^{-3}\right)$ into gravity and dynamic topography (for the mantle part we consider a full dynamic effect of the density anomalies contributing to the residual topography, which depends on the mantle viscosity), $g_{\text {res }}$ (mGal) and $t_{\text {res }}$ $(\mathrm{km})$ are the mantle gravity anomalies and residual topography, and $k=2 \pi G \rho_{\mathrm{t}}$ is the scaling coefficient normalizing the topography units $(\mathrm{km})$ with respect to the gravity $(\mathrm{mGal}$; $G$ is the gravitational constant and $\rho_{\mathrm{t}}$ is the density of the topography). The regularization condition requires that the calculated density anomalies are close to the initial model $\rho_{\text {ini }}$, where $\alpha$ is the relative damping factor. The inversion is performed in the spherical harmonic domain. For the dynamic topography $t_{\text {dynamic }}=B \rho$, we use a vertical viscositydepth profile constrained by mineral physics and geodynamic models (Kaban et al., 2015). The method has been extensively tested on synthetic models (Kaban et al., 2015). It has been demonstrated that the shapes of the calculated density anomalies are correctly reproduced even when they are not resolved in the initial model. However, the amplitude of the values obtained in the inversion density variations might be reduced by damping. We take into account this condition when interpreting the results. The technical details and numerical tests proving the resistance of the solution to plausible changes in the inversion parameters can be found in Kaban et al. (2015) and the Supplement.

The model setup is the same as that in Kaban et al. (2015, 2016c). The residual fields and initial density model were extended to the whole Earth, which is required for decomposition into spherical harmonics. The same global model as described above was used for these purposes. The initial tomography model of Schaeffer and Lebedev (2013) is global; therefore, it was converted to densities using the same approach as in the study area. Density variations were calculated for seven layers with the central depth at 15, 45, 100, $150,200,250$, and $300 \mathrm{~km}$. The density perturbations in the 


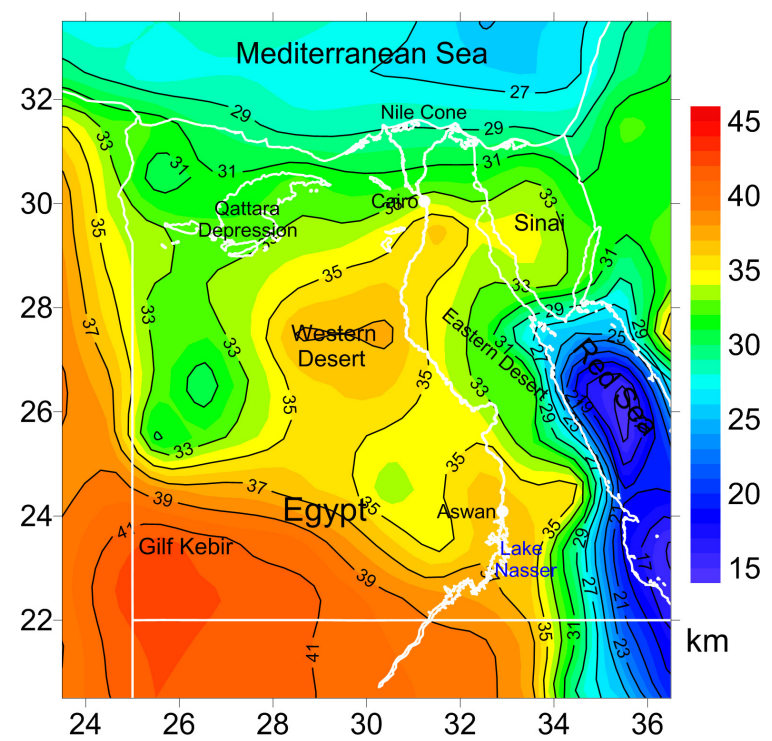

Figure 7. The new Moho map corrected in the joint inversion of the residual gravity and residual topography.

upper layer adjust the potential uncertainties of the crustal densities. The calculated density perturbations to the initial model at the depth $45 \mathrm{~km}$ in the continental part were recalculated in the corrections of the initial Moho model using the crust-mantle density contrast from the reference model (Table 1).

The corrected Moho map is shown in Fig. 7. As expected, the maximal correction $(-3.6 \mathrm{~km})$ is calculated in the northern part of the study area, which is not covered by seismic data. In other areas, it does not exceed $\pm 2 \mathrm{~km}$; this value corresponds to the uncertainty of the seismic determinations. The Moho correction was applied to the continental part only, where the Moho depth exceeds $30 \mathrm{~km}$. It remains unmodified for the Red Sea and Mediterranean. Three slices of the obtained 3-D density model based on joint inversion of the residual gravity and topography constrained by the tomography-based initial model are shown in Fig. 8. The calculated density anomalies range from -35 to $50 \mathrm{~kg} \mathrm{~m}^{-3}$ (Fig. 8a-c) and the final model significantly differs from the initial density model (Fig. 8d-f). Compared to the large-scale model of the whole Middle East, the present results clearly show the fragmentation of the upper mantle in Egypt. The central part and the Qattara Depression are characterized by an increased density of the mantle, which extends to the Mediterranean maximum at a depth of $100 \mathrm{~km}$ (Fig. 8d). At greater depths, the central Egyptian maximum extends to the southeast (Fig. 8e, f). The negative anomaly is localized over the Red Sea and some surroundings at the boundary of the Western Desert and Nubian Shield and limited to a depth of $\sim 150 \mathrm{~km}$, disappearing at greater depths. The local positive anomaly corresponds to the Sinai massif (Fig. 8e, f).

\section{Discussion}

\subsection{Fragmentation of the lithosphere in Egypt based on its density structure}

We further discuss seven 2-D profiles showing density variations relative to the reference model (Figs. 9, 10). Because the vertical resolution is limited to $35-50 \mathrm{~km}$ according to the model setup, the anomaly in the crust might be smeared to the uppermost layer of the mantle ( $>50 \mathrm{~km}$ ), especially in offshore areas with thin crust.

The negative density anomaly under the northern Red Sea is limited to the uppermost mantle as shown in profile 1 (Fig. 9) and agrees with previous conclusions with respect to the passive origin of the extension in this area (e.g., Bosworth, 2015). This anomaly does not continue to Sinai, which is characterized by zero or slightly increased density anomalies in the upper mantle. The seismicity is mainly localized in the crust, which is characterized by an extremely low relative density likely related to the weak layer that is prone to strong deformations, resulting in seismic events. It is also clear that most of the earthquakes are of low magnitude and their hypocenters are concentrated in the crust and confined to the Red Sea rift. This might be related to the shallow Moho discontinuity, which is characterized by a high-temperature and low-density mantle material underneath. Therefore, the stress is not accumulated for a long time. The continuous release of the stress thus generates permanent seismicity characterized by shallow depths and low magnitudes.

The distribution of anomalous density and seismicity from the Nile Delta to southern Egypt is clearly indicated in profile 2 (Fig. 9). It is well known that the Nile Delta is characterized by very low seismic activity compared to the surrounding area (Fig. 1). The constructed density model can provide some explanation for this phenomenon. It is clear from Fig. 9 (profile 2) that this area corresponds to a dense and likely strong mantle lithosphere extending to the bottom of the crust. It has been demonstrated that seismicity occurs at the boundaries of rigid lithospheric blocks in similar situations (Tesauro et al., 2015). In the case of the Nile Delta, the weak crust easily accommodates relatively small deformations, which in contrast to the Red Sea are limited by the strong lithosphere beneath.

The Qattara Depression is also characterized by the highdensity lithosphere overlain with relatively low-density crust (Fig. 9, profile 3). The high-density zone in the mantle deepens to the north and is localized at depths of $200-250 \mathrm{~km}$ in Middle Egypt. In the east, the high-density lithosphere extends to the Suez line (Fig. 10, profile 4), which clearly marks the boundary between the strong lithosphere in western Egypt and the weaker lithosphere in the east. This result agrees with estimations of the effective elastic thickness of the lithosphere based on the cross-spectral analysis of the gravity field (Chen et al., 2015). The seismicity behavior at 

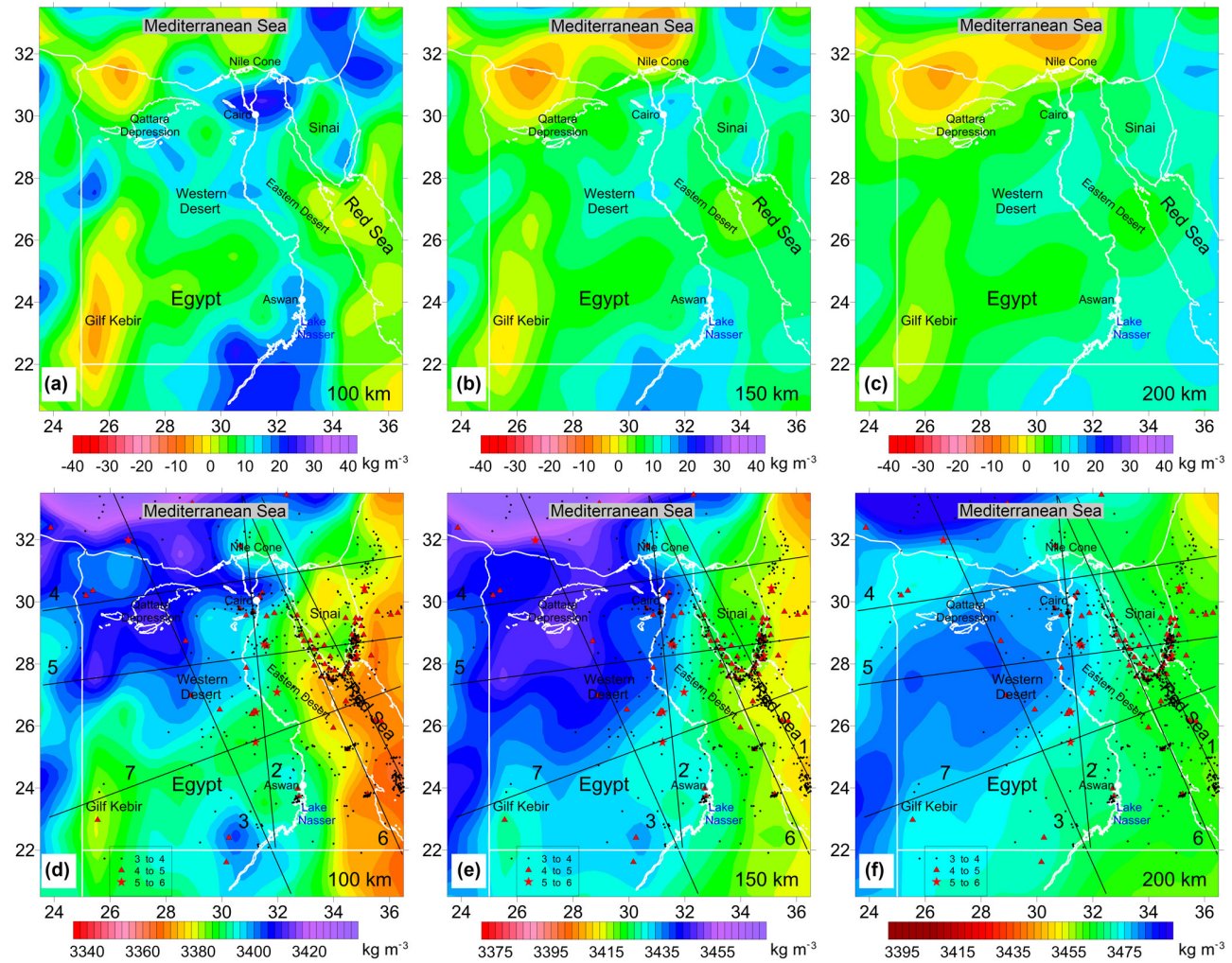

Figure 8. Results of the inversion. (a-c) Calculated density perturbations to the initial model (Fig. 5) at the depths 100 , 150, and $200 \mathrm{~km}$. (d-f) Final density variations at the same depths. Black lines show the location of the profiles in Fig. 9. Black dots, red triangles, and stars show the seismicity of Egypt (magnitudes $>3$ ).

the edge of the high-density lithosphere block is similar to that at the southern border of the Nile Delta (Fig. 9, profile 2). Further to the south, the transition between different lithosphere blocks is smoother; the high-density lithosphere gradually deepens from the Western Desert to Sinai (Fig. 10, profile 5).

The crustal and mantle structure along the Suez Canal and Gulf of Suez is shown in profile 6 (Fig. 10). One of the vital problems discussed for these structures is the cessation of the opening of the Gulf of Suez rift. It is observed that the boundary between the Gulf and Isthmus of Suez corresponds to the boundary between the lithospheric blocks with different densities (Fig. 10, profile 6). The high-density block in the southeastern Mediterranean located to the north of the Suez Canal and Gulf of Suez might terminate the prolongation of the Gulf of Suez rift further to the north. It also manifests the significant decrease in seismicity in the Isthmus of Suez and further to the north. Therefore, the stronger lithosphere in the north might prevent the continuation of the Gulf of Suez opening as was initially proposed by Steckler and ten Brink (1986).

The high-density block is observed in the area of Gilf Kebir in southwestern Egypt, as indicated in profile 7 of Fig. 10, with no associated seismicity revealing the stability of this region, which is characterized by Paleozoic outcrop. This anomaly is already observed in the initial seismic tomography model; therefore it is likely related to relatively low temperatures. A low-density anomaly likely related to a high thermal regime can be observed in the northern Red Sea associated with high earthquake activity (Profile 7, Fig. 10). The lithosphere structure becomes asymmetric across the northern Red Sea rift, which corresponds to the asymmetric pattern of the seismicity relative to the central axis of the northern Red Sea. The intensive seismicity is concentrated on the western side, where the lithosphere is weakened at a depth of $100 \mathrm{~km}$ (profile 7, Fig. 10). Further to the north, the seismicity pattern is divided into two branches (Fig. 2). The Red Sea zone continues towards the Gulf of Suez (Fig. 1). Another branch extends along the Dead Sea Transform fault, which is also characterized by high seismic activity. To conclude, the seismicity asymmetrically tends to the west of the northern Red Sea rift, possibly because the opening of the northern Red Sea rift is directed W-N-W to the Gulf of Suez, which is associated with the weakened lithosphere. 


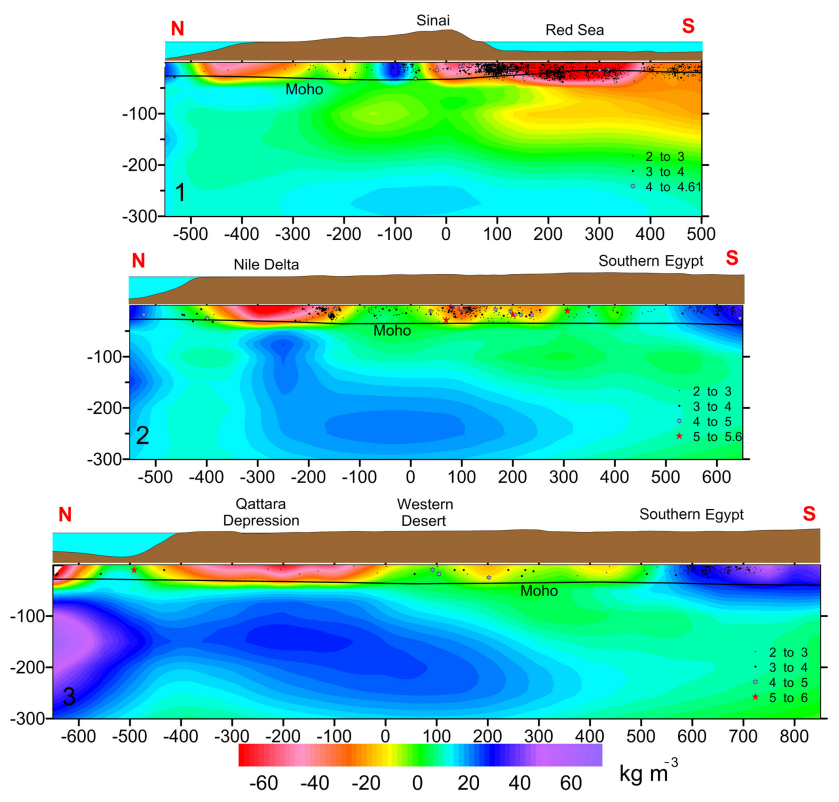

Figure 9. Density anomalies relative to the reference model (Table 1) along selected profiles. Profiles 1-3, Fig. 8d-f. Black dots indicate the hypocenters of the earthquakes projected onto the profiles (ENSN earthquake catalogues).

\subsection{Isostatic gravity anomalies and their relation to seismicity}

The local isostatic anomalies seen in the upper crust density heterogeneities, which are not included in the initial model, are particularly not completely compensated for in a local isostasy sense but rather supported by the rigid lithosphere. They can be generated by various processes (e.g., mantle intrusions in the upper crust, faulting, and subduction) and could be associated with significant stresses in the lithosphere. Therefore, isostatic anomalies of the gravity field are often used to study active seismic areas (e.g., Assumpção and Sacek, 2013; Sobiesiak et al., 2007). However, the feasibility of this approach strongly depends on the isostatic model that was used to calculate the isostatic anomalies. The standard simple models (Airy and Pratt) are based on the observed topography and do not adequately describe the real density structure of the crust and upper mantle, which can cause artificial anomalies (e.g., Kaban et al., 2016b). Therefore, it is important to take into account as much as possible actual information about the crustal structure in the study area, which can be obtained from other geophysical and geological methods. In our approach, we intend to separate the gravity anomalies that are chiefly related to the density inhomogeneities in the crust and are not compensated for in both ways: via the density heterogeneity of the lithosphere or dynamically from the mantle. Therefore, the residual anomalies not adjusted in the inversion represent a large-scale part of

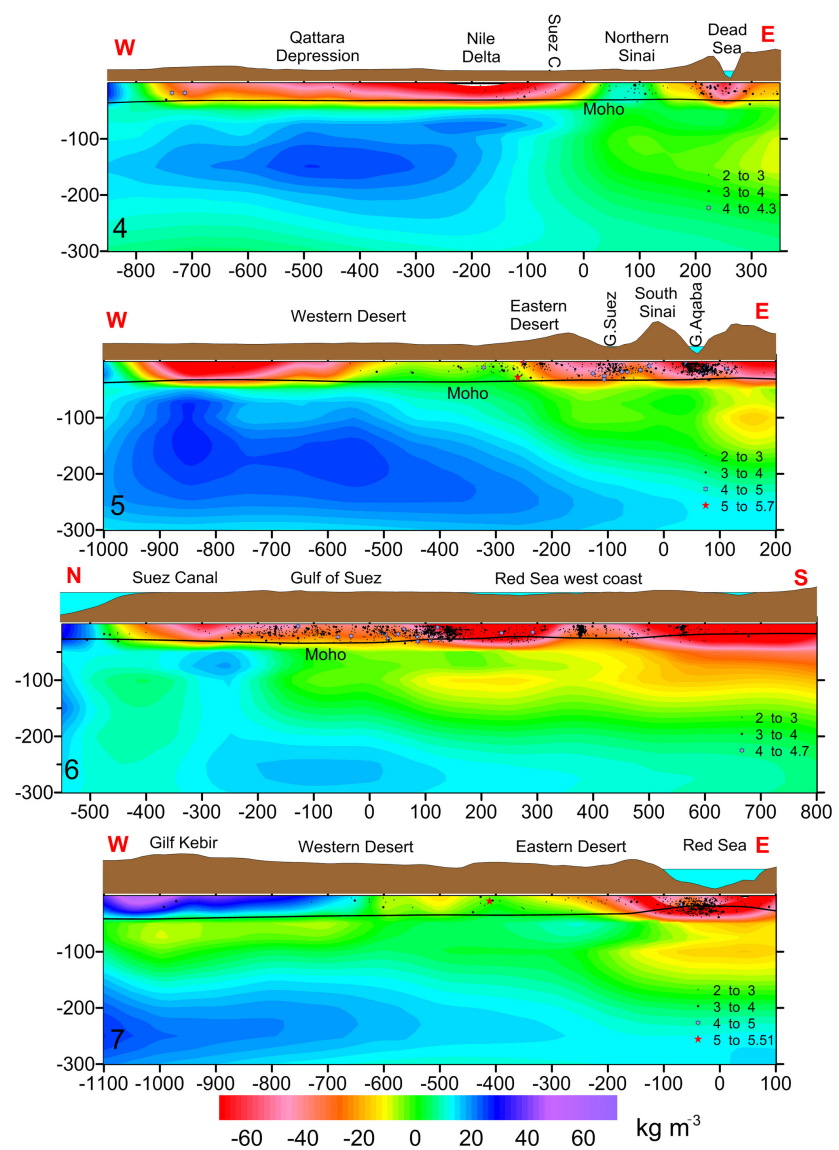

Figure 10. Density anomalies along selected profiles (4-7), Fig. 8d-e. Notations are as in Fig. 9.

the isostatic anomalies, which might be responsible for the stress concentration and seismicity.

The isostatic anomalies analyzed in this study are compiled in the following way. First, we use the residual part of the mantle gravity anomalies (Fig. 6a), which is not fit in the inversion. This is a long-wavelength field (the resolution is $1 \times 1^{\circ}$ corresponding to degree / order 180), which is characterized by small amplitudes (around $\pm 10 \times 10^{-5} \mathrm{~m} \mathrm{~s}^{-2}$, $\mathrm{mGal}$ ). This field has been complemented by the local part of the isostatic anomalies, which were computed in a previous study for a high-resolution grid (Kaban et al., 2016b). The total isostatic anomalies are shown in Fig. 11. Their resolution corresponds to the resolution of the initial gravity field model EIGEN-6c4 $(\max 10 \times 10 \mathrm{~km})$.

The isostatic anomalies demonstrate very diverse patterns in Egypt and its surroundings. The strongest variations $\left( \pm 90 \times 10^{-5} \mathrm{~m} \mathrm{~s}^{-2}, \mathrm{mGal}\right)$ are found in the southeastern part along the Red Sea and Sinai Peninsula (Fig. 11). Sinai is bounded by linear anomalies parallel to the Gulf of Suez and Gulf of Aqaba, which are clearly associated with high levels of seismicity. 


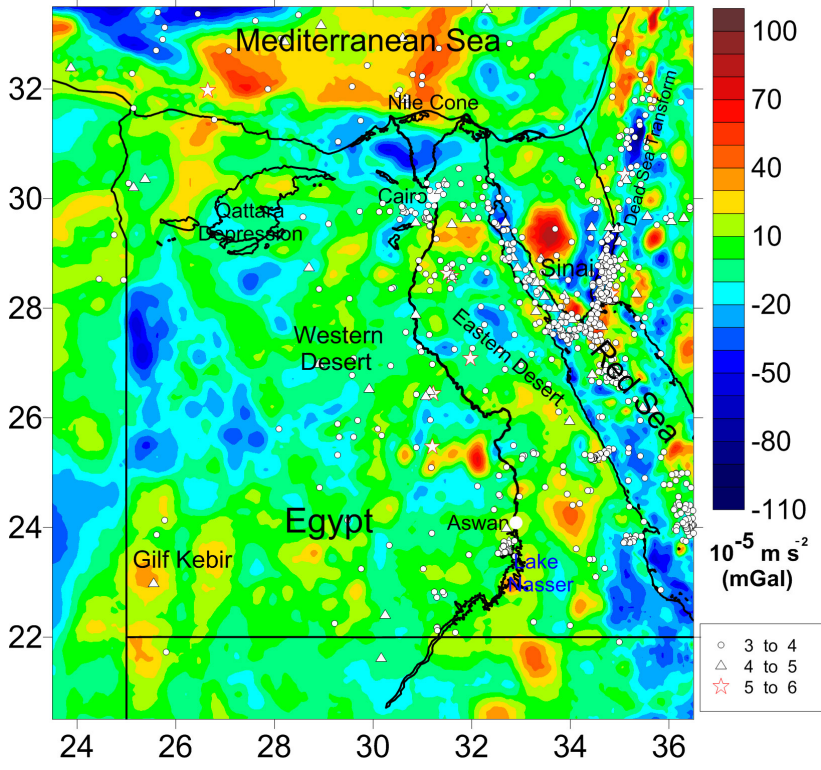

Figure 11. Isostatic anomalies of the gravity field and seismicity. Earthquakes are shown for $M>3$ (Egyptian National Seismological Catalogue, ENSN, 1998-2011).

The whole Sinai Peninsula is divided into several parts with different patterns of isostatic anomalies. The central block with very high anomalies up to $100 \times 10^{-5} \mathrm{~m} \mathrm{~s}^{-2}$ (mGal) demonstrates very low seismic activity. It is divided from the southern part by a narrow high-amplitude negative anomaly (Fig. 11). The relatively strong earthquakes (M.3) tend to occur in zones with high gradients of isostatic anomalies (Figs. 11 and 12a). This tendency persists to the west over the Nile Valley and Eastern Desert. The seismicity in the Red Sea is also concentrated in the high-gradient zones. This certainly concerns only some of the earthquakes; earthquakes are also generated by deformations related to plate motions, but the general tendency is clear.

The broad negative anomalies in the western part of the area and over the Qattara Depression likely indicate the increased thickness of the low-density upper crust with no seismic activity associated. In the same way, the broad negative anomaly over the Nile Delta indicates that the density of sediments is slightly overestimated in the initial model. The high-amplitude isostatic anomalies in the Mediterranean might be related to the subduction of the African lithosphere under Eurasia.

We found some relationship between the isostatic anomalies (with their gradients) and magnetic anomalies (Fig. 12b). The E-W Raqabet El-Naam fault in central Sinai represents a fundamental boundary, which clearly marks changes in the isostatic gravity anomalies, magnetic field patterns, and the seismicity (Fig. 12). The area to the south represents a high-gradient zone (both in magnetic and isostatic gravity anomalies), which is characterized by increased seismic activity. The nearly circular positive magnetic anomaly in the
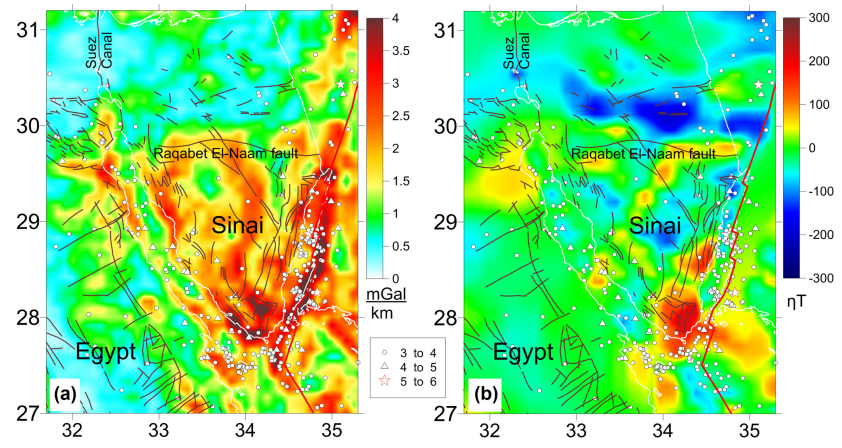

Figure 12. (a) Maximal values of the horizontal gradients of the isostatic anomalies (filtered $\lambda>25 \mathrm{~km}$ to remove small-scale variations); (b) magnetic anomalies (Maus et al., 2007). Other notations are as in Fig. 11.

south corresponds well to the positive isostatic anomaly pattern. This block is characterized by the uplifted basement and bounded by a swarm of earthquakes.

\section{Conclusions}

A joint analysis of the new satellite-terrestrial model of the gravity field and recent data on the crustal structure and tomography was performed to create an integrative model of the crust and upper mantle and to investigate the relationship between the isostatic state of the lithosphere and seismicity. The following conclusions can be drawn.

1. This study reveals a distinct fragmentation of the lithosphere of Egypt into several blocks characterized by different properties.

The central area and the Qattara Depression are characterized by an increased density of the mantle, which extends to the Mediterranean maximum at a depth of $100 \mathrm{~km}$. At the same time, the crystalline crust in this area demonstrates low average seismic velocities and density, which might indicate an increased thickness of the relatively low-density upper crust.

The central Egyptian maximum of the upper mantle density extends to the southeast in the middle to upper mantle and is localized at depths of $\sim 170-270 \mathrm{~km}$. The same trend is found in the W-E direction; however, it is limited by the western part of the Eastern Desert.

In the northeastern part of Egypt, the high-density lithosphere is bounded by the Gulf of Suez, which marks the transition between the typically strong and cold plate and the weakened lithosphere. Thus, the opening of the Suez rift further to the north might be blocked by the strong lithosphere of the Isthmus of Suez in the northern direction.

The Sinai microplate is characterized, on average, by the normal density of the upper mantle; however, 
smaller-scale features cannot be resolved at these depths because they are already smoothed out in the gravity field. In contrast, the upper crust, which is reflected in the isostatic anomalies, demonstrates large density variations. The central block has a strong maximum, which should correspond to the strong and dense crust.

The negative mantle anomaly in the northern Red Sea is limited to the uppermost mantle, which confirms the passive origin of this structure. The density structure of the lithosphere in the northern Red Sea is asymmetric; the western side is characterized by low densities at a depth of $\sim 100 \mathrm{~km}$, which likely corresponds to the hot weakened layer.

2. The density structure of the lithosphere is closely related to the seismicity distribution.

The low seismicity in the Nile Delta and Suez Canal might be related to the increased strength of the lithosphere, which is associated with densification due to low temperatures. It prevents strong deformations; the weak crust accommodates insignificant strains.

The low-density and likely weak upper crust and uppermost layer of the mantle in the northern Red Sea are characterized by high seismic activity. Most earthquakes are of low magnitudes at shallow depths and are located to the west of the axial depression of the Red Sea rift, which is characterized by the low-density and likely weak uppermost mantle. Thus, earthquakes are confined to the crust and uppermost mantle, where the low strength provokes stress release.

3. We found a correlation between the variations in isostatic anomalies and seismicity. High-amplitude and localized isostatic anomalies generally correspond to areas with high seismic activity. This tendency is especially visible in Sinai, which is bounded by strong linear isostatic anomalies with a corresponding increase in seismic activity. Less pronounced but still visible, this relationship extends to the west, including the Nile Valley and Western Desert, and to the northern Red Sea.

Data availability. The gravity data are available from the International Centre for Global Earth Models (ICGEM; http:// icgem.gfz-potsdam.de/home, last access: 29 June 2018; Förste et al., 2014). The tomography model of Schaeffer and Lebe$\operatorname{dev}(2013)$ is available from the website of the first author (https: //andrewjschaeffer.wordpress.com/tomography/sl2013sv/, last access: 29 June 2018: Schaeffer and Lebedev, 2013). The data on the crustal structure are available by contacting the corresponding authors.

Author contributions. MKK and SEK conceived the study. MKK carried out the gravity data analysis and construction of the 3-D density model. SEK and NAA carried out the analysis of seismicity and its relation to the lithosphere density distribution and isostatic anomalies. MKK, SEK, and NAA contributed to interpretation of the results and conclusions and wrote the paper.

Competing interests. The authors declare that they have no conflict of interest.

Acknowledgements. The authors are grateful to Alexander Minakov, Bart Root, and Mioara Mandea for their valuable comments that helped to improve the paper greatly. The authors extend their appreciation to the International Scientific Partnership Program ISPP King Saud University for funding this research work through ISPP no. 0052.

The article processing charges for this open-access publication were covered by a Research Centre of the Helmholtz Association.

Edited by: Mioara Mandea

Reviewed by: Bart Root and Alexander Minakov

\section{References}

Abdelwahed, M. F., El-Khrepy, S., and Qaddah, A.: Threedimensional structure of the Conrad and Moho discontinuities in Egypt, J. Afr. Earth Sci., 85, 87-102, 2013.

Assumpção, M. and Sacek, V.: Intraplate seismicity and flexural stresses in central Brazil, Geophys. Res. Lett., 40, 487-491, 2013.

Azab, A., El-Khadragy, A., and Soliman, S. A.: Egyptian Crust: A structural model based on gravity and seismic data, J. Am. Sci., 11, 216-229, 2015.

Bosworth, W.: Geological evolution of the Red Sea: historical background, review, and synthesis, in: The Red Sea, 45-78, Springer Berlin Heidelberg, 2015.

Chen, B., Kaban, M. K., El Khrepy, S., and Al-Arifi, N.: Effective elastic thickness of the Arabian plate: Weak shield versus strong platform, Geophys. Res. Lett., 42, 3298-3304, https://doi.org/10.1002/2015GL063725, 2015.

Christensen, N. I. and Mooney, W. D.: Seismic velocity structure and composition of the continental crust: a global review, J. Geophys. Res., 100, 9761-9788, 1995.

Corchete, V., Chourak, M., Hussein, H. M., Atiya, K., and Timoulali, Y.: Crustal and upper mantle structure of the north-east of Egypt and the Afro-Arabian plate boundary region from Rayleigh-wave analysis, J. Afr. Earth Sci., 129, 195-201, 2017.

Cowie, L. and Kusznir, N.: Mapping crustal thickness and oceanic lithosphere distribution in the Eastern Mediterranean using gravity inversion, Petrol. Geosci., 18, 373-380, 2012.

Egyptian Geologic Survey and Mining Authority (EGSMA): Geological map of Egypt, 1991.

Egyptian National Seismological Catalogues (1997-2013): National Research Institute of Astronomy and Geophysics NRIAG, Helwan ,Cairo Egypt, published by NRIAG from 1997 to 2013. 
El Khrepy, S., Koulakov, I., and Al-Arifi, N.: Crustal structure in the area of the "Cannon Earthquakes" of Abu Dabbab (Northern Red Sea, Egypt), from seismic tomography inversion, B. Seismol. Soc. Am., 105, 1870-1882, https://doi.org/10.1785/0120140333, 2015.

El Khrepy, S., Koulakov, I., Al-Arifi, N., and Petrunin, A. G.: Seismic structure beneath the Gulf of Aqaba and adjacent areas based on the tomographic inversion of regional earthquake data, Solid Earth, 7, 965-978, https://doi.org/10.5194/se-7-965-2016, 2016a.

El Khrepy, S., Koulakov, I., and Al-Arifi, N.: Crustal and uppermost mantle structure beneath the continental rifting area of the Gulf of Suez from earthquake tomography, Tectonophysics, 668-669, 92-104, 2016b.

Förste, C., Bruinsma, S., Abrikosov, O., Flechtner, F., Marty, J. C., Lemoine, J. M., and Biancale, R.: EIGEN-6C4 - The latest combined global gravity field model including GOCE data up to degree and order 1949 of GFZ Potsdam and GRGS Toulouse, in: EGU General Assembly Conference Abstracts, May 2014, Vol. 16, 3707 pp., 2014.

Fullea, J., Afonso, J. C., Connolly, J. A. D., Fernandez, M., GarcíaCastellanos, D., and Zeyen, H.: LitMod3D: An interactive 3D software to model the thermal, compositional, density, seismological, and rheological structure of the lithosphere and sublithospheric upper mantle, Geochem. Geophys. Geosyst., G3, 10, https://doi.org/10.1029/2009GC002391, 2009.

Gradmann, S., Ebbing, J., and Fullea, J.: Integrated Geophysical Modeling of the Lateral Transition Zone in Lithospheric Mantle under Norway and Sweden, Geophys. J. Int., 194, 1358-1373, 2013.

Hosny, A. and Nyblade, A.: The crustal structure of Egypt and the Northern Red Sea region, Tectonophysics, 687, 257-267, 2016.

Kaban, M. K. and Mooney, W. D.: Density structure of the lithosphere in the southwestern United States and its tectonic significance, J. Geophys. Res., 106, 721-739, https://doi.org/10.1029/2000JB900235, 2001.

Kaban, M. K., Tesauro, M., and Cloetingh, S.: An integrated gravity model for Europe's crust and upper mantle, Earth Planet. Sci. Lett., 296, 195-209, https://doi.org/10.1016/j.eps1.2010.04.041, 2010.

Kaban, M. K., Tesauro, M., Mooney, W. D., and Cloetingh, S.: Density, temperature, and composition of the North American lithosphere - New insights from a joint analysis of seismic, gravity, and mineral physics data: 1 . Density structure of the crust and upper mantle, Geochem. Geophys. Geosyst., G3, 15, https://doi.org/10.1002/2014GC005483, 2014a.

Kaban, M. K., Petrunin, A. G., Schmeling, H., and Shahraki, M.: Effect of decoupling of lithospheric plates on the observed geoid, Surv. Geophys., 35, 1361-1373, https://doi.org/10.1007/s10712014-9281-3, 2014b.

Kaban, M. K., Mooney, W. D., and Petrunin, A. G.: Cratonic root beneath North America shifted by basal drag from the convecting mantle, Nat. Geosci., 8, 797-800, https://doi.org/10.1038/ngeo2525, 2015.

Kaban, M. K., Stolk, W., Tesauro, M., El Khrepy, S., Al-Arifi, N., Beekman, F., and Cloetingh, S.: 3D density model of the upper mantle of Asia based on inversion of gravity and seismic tomography data, Geochem. Geophys. Geosyst., G3, 17, https://doi.org/10.1002/2016GC006458, 2016a.
Kaban, M. K., El Khrepy, S., and Al-Arifi, N.: Isostatic Model and Isostatic Gravity Anomalies of the Arabian Plate and Surroundings, Pure Appl. Geophys., 173, 1211-1221, https://doi.org/10.1007/s00024-015-1164-0, 2016b.

Kaban, M. K., El Khrepy, S., Al-Arifi, N., Tesauro, M., and Stolk, W.: Three-dimensional density model of the upper mantle in the Middle East: Interaction of diverse tectonic processes, J. Geophys. Res. Sol. Earth., 121, 5349-5364, https://doi.org/10.1002/2015JB012755, 2016c.

Krystopowicz, N. J. and Currie, C. A.: Crustal eclogitization and lithosphere delamination in orogens, Earth Planet. Sci. Lett., 361, 195-207, 2013.

Maus, S., Sazonova, T., Hemant, K., Fairhead, J. D., and Ravat, D.: National geophysical data center candidate for the world digital magnetic anomaly map, Geochem. Geophys. Geosyst., 8, 1-10, 2007.

McClusky, S., Balassanian, S., Barka, A., Demir, C., Ergintav, S., Georgiev, I., and Kastens, K.: Global Positioning System constraints on plate kinematics and dynamics in the eastern Mediterranean and Caucasus, J. Geophys. Res.-Solid Earth, 105, 56955719, 2000.

McClusky, S., Reilinger, R., Mahmoud, S., Sari, D. B., and Tealeb, A.: GPS constraints on Africa (Nubia) and Arabia plate motions, Geophys. J. Int., 155, 126-138, 2003.

Mohamed, A. A., Gao, S. S., Elsheikh, A. A., Liu, K. H., Yu, Y., and Fat-Helbary, R. E.: Seismic imaging of mantle transition zone discontinuities beneath the northern Red Sea and adjacent areas, Geophys. J. Int., 199, 648-657, https://doi.org/10.1093/gji/ggu284, 2014.

Molinari, I. and Morelli, A.: EPcrust: a reference crustal model for the European Plate, Geophys. J. Int., 185, 352-364, 2011.

Mooney, W. D.: Crust and Lithospheric Structure-Global Crustal Structure, Seismol. Struct. Earth: Treatise on Geophysics, 1, p. 361, 2010.

Mooney, W. D. and Kaban, M. K.: The North American Upper Mantle: Density, Composition, and Evolution, J. Geophys. Res., 115, B12424, https://doi.org/10.1029/2010JB000866, 2010.

Prutkin, I. and Saleh, A.: Gravity and magnetic data inversion for 3D topography of the Moho discontinuity in the northern Red Sea area, Egypt, J. Geodyn., 47, 237-245, 2009.

Ritsema, J., Deuss, A. A., Van Heijst, H. J., and Woodhouse, J. H.: S40RTS: a degree-40 shear-velocity model for the mantle from new Rayleigh wave dispersion, teleseismic traveltime and normal-mode splitting function measurements, Geophys. J. Int., 184, 1223-1236, 2011.

Rybakov, M. and Segev, A.: Top of the crystalline basement in the Levant, Geochem. Geophys. Geosyst., G3, 5, 1-8, 2004.

Salem, A., Green, C., Campbell, S., Fairhead, J. D., Cascone, L., and Moorhead, L.: Moho depth and sediment thickness estimation beneath the Red Sea derived from satellite and terrestrial gravity data, Geophysics, 78, G89-G101, 2013.

Schaeffer, A. J. and Lebedev, S.: Global shear-speed structure of the upper mantle and transition zone, Geophys. J. Int., 194, 417-449, 2013.

Segev, A., Rybakov, M., Lyakhovsky, V., Hofstetter, A., Tibor, G., Goldschmidt, V., and Avraham, Z. B.: The structure, isostasy and gravity field of the Levant continental margin and the southeast Mediterranean area, Tectonophysics, 425, 137-157, 2006. 
Sobh, M., Ebbing, J., and Götze, H. J.: The lithospheric structure of Egypt and its surroundings by joint analysis of terrestrial and satellite gravity observations, March 2016, Münster, Germany, DGG: 76th Annual Meeting of the DGG (German Geophysical Society), A238, 3E.005, 2016.

Sobiesiak, M., Meyer, U., Schmidt, S., Götze, H. J., and Krawczyk, C. M.: Asperity-generating upper crustal sources revealed by $b$ value and isostatic residual anomaly grids in the area of Antofagasta, Chile, J. Geophys. Res.-Solid Earth, 112, 1-11, 2007.

Steckler, M. S. and ten Brink, U. S.: Lithospheric strength variations as a control on new plate boundaries: examples from the northern Red Sea region, Earth Planet. Sci. Lett., 79, 120-132, 1986.

Stern, R. J. and Johnson, P.: Continental lithosphere of the Arabian Plate: A geologic, petrologic, and geophysical synthesis, EarthSci. Rev., 101, 29-67, 2010.

Stixrude, L. and Lithgow-Bertelloni, C.: Thermodynamics of mantle minerals - I. Physical properties, Geophys. J. Int., 162, 610632, 2005.
Stolk, W., Kaban, M. K., Beekman, F., Tesauro, M., Mooney, W. D., and Cloetingh, S.: High-resolution regional crustal models from irregularly distributed data: Application to Asia and adjacent areas, Tectonophysics, 602, 55-68, 2013.

Szwillus, W. and Ebbing, J.: The uncertainty of seismic crustal models and the feedback on mantle residual gravity, Abstract TB43B3037 presented at 2016 Fall Meeting, AGU, San Francisco, CA, 12-16 December, 2016.

Tesauro, M., Kaban, M. K., Mooney, W. D., and Cloetingh, S.: Density, temperature, and composition of the North American lithosphere - New insights from a joint analysis of seismic, gravity, and mineral physics data: 2 . Thermal and compositional model of the upper mantle, Geochem. Geophys. Geosyst., G3, 4808-4830, https://doi.org/10.1002/2014GC005484, 2014.

Tesauro, M., Kaban, M. K., and Mooney, W. D.: Variations of the lithospheric strength and elastic thickness in North America, Geochem. Geophys. Geosyst., G3, 2197-2220, https://doi.org/10.1002/2015GC005937, 2015. 